OPEN ACCESS

Edited by:

Andreas Charidimou, Harvard Medical School,

United States

Reviewed by:

W. Taylor Kimberly,

Harvard Medical School,

United States

Eitan Auriel,

Partners HealthCare,

United States

Henry Ma,

Monash University, Australia

Craig S. Anderson,

University of Sydney, Australia

${ }^{*}$ Correspondence:

Lu-sha Tong

2310040@zju.edu.cn;

Feng Gao

2202012@zju.edu.cn

tThese authors have contributed equally to this work.

Specialty section:

This article was submitted to Stroke, a section of the journal

Frontiers in Neurology

Received: 31 August 2017 Accepted: 28 November 2017 Published: 15 December 2017

Citation:

Xu X-h, Gao T, Zhang W-j,

Tong L-s and Gao F (2017)

Remote Diffusion-Weighted Imaging Lesions in Intracerebral Hemorrhage: Characteristics, Mechanisms, Outcomes, and

Therapeutic Implications. Front. Neurol. 8:678. doi: 10.3389/fneur.2017.00678

\section{Remote Diffusion-Weighted Imaging Lesions in Intracerebral Hemorrhage: Characteristics, Mechanisms, Outcomes, and Therapeutic Implications}

\author{
Xu-hua Xu $u^{1,2}$, Ting Gao', Wen-ji Zhang ${ }^{3}$, Lu-sha Tong ${ }^{4 * t}$ and Feng Gao ${ }^{1,4 * t}$ \\ ${ }^{1}$ School of Medicine, Zhejiang University, Hangzhou, China, ${ }^{2}$ Department of Neurology, The Fourth Affiliated Hospital, School \\ of Medicine, Zhejiang University, Yiwu, China, ${ }^{3}$ Department of Radiology, The Fourth Affiliated Hospital, School of Medicine, \\ Zhejiang University, Yiwu, China, ${ }^{4}$ Department of Neurology, The Second Affiliated Hospital, School of Medicine, Zhejiang \\ University, Hangzhou, China
}

Spontaneous intracerebral hemorrhage $(\mathrm{ICH})$ is one of the most fatal form of stroke, with high mortality and disability rate. Small diffusion-weighed imaging lesions are not rare to see in regions remote from the hematoma after $\mathrm{ICH}$ and have been generally considered as related with poor outcome. In this review, we described the characteristics of remote ischemic lesions, discussed the possible mechanisms and clinical outcomes of these lesions, and evaluated the potential therapeutic implications.

Keywords: intracerebral hemorrhage, secondary brain injury, remote diffusion-weighed imaging lesions, microangiopathy, blood pressure lowering

\section{INTRODUCTION}

Spontaneous intracerebral hemorrhage ( $\mathrm{ICH})$, defined as non-traumatic bleeding into the brain parenchyma (1), is the second most common cause of stroke (2), accounting for about $10-15 \%$ of all strokes worldwide each year (3), but $27-51 \%$ in Chinese population (4). Despite significant progress in clinical treatment, only $12-26 \%$ patients are able to lead independent lives at 12 months after ICH onset, and the mortality rate remains high, reported from 40 to $50 \%$ (5). It has been widely accepted that the hematoma could not only cause direct destruction of brain parenchymal tissue due to the mass effect known as primary injury (6) but also secondary brain injury, including perihematomal edema (PHE), secondary ischemic injury, and secondary micro-hemorrhage, each of which may lead to severe neurological deficits and sometimes delayed fatality $(7,8)$. Secondary ischemic lesions after ICH, both in perihematomal region (9-17) and remote region from the hematoma $(9,18-27)$ have been described recently. It is presumed that perihematomal lesion is related with decreased cerebral blood flow (CBF) around hematoma, and the mechanisms involved microvascular compromise, or bioenergetic compromise (9-17). While for remote site ischemic lesions, the underlying mechanisms are quite different. Diffusion-restricted lesions on diffusionweighted imaging (DWI) are detected in $11.1-41 \%$ ICH patients remote from the hematoma $(9,18-27)$. Thus, they have been generally considered as cerebral infarcts. They are described as small, cortical, or subcortical, single or multiple, and topographically distant from the hematoma. They are often subclinical, but was reported associating with worsened outcome (20,23, 24). Hence, it is important to understand the pathophysiology of these remote ischemic lesions after ICH for clinical practice. In this review, we first describe the characteristics and clinical outcomes of 
remote DWI lesions, then we discuss the possible mechanisms behind these lesions, which may provide clues for its potential therapeutic implications to $\mathrm{ICH}$.

\section{CHARACTERISTICS OF REMOTE DWI LESIONS}

Acute ischemic lesions can be identified with high accuracy by using DWI technique ( $88-100 \%$ sensitivity and $95-100 \%$ specificity) (28). With DWI, lesions with restricted diffusion have been observed in 11.1-41\% of patients with acute ICH (Table 1) $(9,18-27)$. These lesions are topographically distant from initial hematoma, and Gioia et al. found that more than half were in the hemisphere contralateral to the hematoma (9). They are mainly located in cortical or subcortical regions and can also be found in basal ganglia (BG), cerebellum, brain stem, or corpus callosum. These DWI lesions are mostly small, dot-like $(<20 \mathrm{~mm}$ diameter or $<0.5 \mathrm{~mL}$ volume), single, or multiple. Some patients are reported as having larger, territorial infarcts, while those patients usually received craniotomy or external ventricular drainage placement (18).

It is well known that spontaneous ICH was related with two different types of vascular disorders. Varied etiologies would lead to different imaging demonstration for ICH. One main etiology for ICH is cerebral amyloid angiopathy (CAA). It is characterized by the progressive accumulation of amyloid in the wall of small arteries and arterioles, which predominantly locate in the leptomeningeal space and cortex (29). Another cause of ICH is hypertension. Hypertension could modify arterial wall properties in another way and induce hyalinization and contribute to decreased elasticity of arteries, especially penetrating arteries located in the BG, thalamus, pons, and cerebellum (30). These pathological changes not only cause the vessel wall to become prone to rupture but also cause dysfunction of $\mathrm{CBF}$ regulation and luminal occlusion. Thus, CAA and hypertensive angiopathy (HA) ICH may both result in high rates of infarction. In a few studies, the DWI lesions were more commonly seen in patients with CAA-related ICH than in patients with HA-related $\mathrm{ICH}$ $(19,22)$. While in some other study, similar frequencies of DWI lesions were observed in both types of $\mathrm{ICH}(21)$. As reported earlier, there is a significant variation of hematoma locations of these two different etiologies. That is, CAA may be more prevalent in lobar $\mathrm{ICH}$, and $\mathrm{HA}$ in deep $\mathrm{ICH}$, which involves BG, thalamus, pons, and cerebellum (31). Despite of this, DWI lesions of these two types of ICH are still mainly located in cortical or subcortical regions, regardless of different etiology. According to the study conducted by Auriel et al., patients with CAA etiology may have relative higher occurrence of lesions in frontal lobe, and patients with HA in parietal lobe (21). The relative different distribution between the two may suggest yet unidentified processes contributing to the infarctions. Another explanation may be that the clinical distinction of CAA and HA is likely to be an oversimplification. In a research of postmortem brains of hypertensive patients with $\mathrm{ICH}$, the authors found that even in deep ICH, CAA may still play a role in the pathogenesis of ICH (32). Hypertension may also be correlated to increased amounts of amyloid- $\beta$ deposited in the brain of ApoE4 carriers (33). And in a histological study of brain tissue obtained during surgery, more than $30 \%$ of CAA-related ICH patients showed multiple microangiopathic change (34). Whether the CAA or $\mathrm{HA}$ are the underlying mechanism of these lesions need further study. Since studies using postmortem brains with DWI lesions is rather rare, animal experimental studies may give us more hints. Moreover, bio-markers of these two pathologies are waiting to be explored.

The accurate time point of DWI lesions occurrence is not clear. The DWI lesions are likely to happen along with the development of ICH. Kang et al. observed that the frequency of DWI lesions at initial observation was only 7.7\%, whereas 5-day MRI imaging showed an increased frequency up to $25 \%$ (24). However, some studies suggested that this effect may only exist at the hyper-acute stage of ICH. In a study conducted by Auriel et al., no difference was shown in frequency of lesions on mean 2 days after ICH and after 14 days in MRI scans (21). In contrast, in a multicenter cross-sectional study, about one-third of DWI lesions were detected within 1 week, $82 \%$ were detected within 1 month, and the latest DWI lesion detected was at 64 days after ICH (19). These findings may indicate an ongoing pathologic process, even in subacute stage of ICH.

The research about the evolution of DWI lesions in $\mathrm{ICH}$ patients is rare. Tsai et al. reported about 52\% DWI lesions disappeared on follow-up T2-weighted or FLAIR imaging at 3 months after ICH, when others were still present in MRI (20). The underlying mechanism about the regression of DWI lesions remains unknown. Clinical observations have reported complete early reversal of hyperintensities on DWI of those clinically diagnosed stroke patients $(35,36)$. In a few of recent research, DWI reversal is mainly associated with small infarct volume in patients with TIA and minor stroke $(37,38)$. Thus, it is hypothesized that regression of a DWI lesion after ICH may indicate minor vasculopathy or transient vascular occlusion with early reperfusion (20).

Despite of numerous studies about DWI lesions after ICH, it is, however, difficult to compare these studies, due to the difference in study design, patient population, time to MRI, and imaging methodology.

\section{MECHANISMS OF REMOTE DWI LESIONS}

There are several potential mechanisms of remote DWI lesions after ICH, including microangiopathy, cerebral atherosclerosis, blood pressure (BP) lowering, remote extension of hematoma, and venous drainage disorder. These mechanisms may interact with each other in complicated ways. For example, it is hypothesized that patients with a greater burden of small vessel disease are at increased risk for loss of cerebral autoregulation during the acute stage of $\mathrm{ICH}$, and ischemia may be precipitated more easily by acute $\mathrm{BP}$ reductions in those patients (39). Besides, distal embolization after cerebral angiography and cardioembolic sources seem plausible mechanisms of DWI lesion development in some ICH patients (9). Although these mechanisms mainly work in acute stage of $\mathrm{ICH}$, it is assumed that some of these mechanisms like microangiopathy keep on working even in subacute stage of ICH (19). 
TABLE 1 | Characteristics of remote DWI lesions.

\begin{tabular}{|c|c|c|c|c|c|c|c|c|}
\hline Sample size & Design & $\mathrm{ICH}$ cause & Time of MRI & Prevalence & Location & Size & Number & Reference \\
\hline \multirow[t]{3}{*}{$78(87 \%$ ICH) } & \multirow{3}{*}{$\begin{array}{l}\text { Retrospective } \\
\text { case-control }\end{array}$} & \multirow[t]{3}{*}{$100 \%$ CAA } & \multirow[t]{3}{*}{$48.7 \%<7$ days post- $\mathrm{ICH}$} & \multirow[t]{3}{*}{$15 \%$} & $64.7 \%$ subcortical & \multirow[t]{3}{*}{ Not mention } & \multirow[t]{3}{*}{1 or 2} & \multirow[t]{3}{*}{ Kimberly et al. (25) } \\
\hline & & & & & $23.5 \%$ cortical & & & \\
\hline & & & & & $11.8 \%$ other & & & \\
\hline \multirow[t]{3}{*}{$118(100 \% \mathrm{ICH})$} & \multirow[t]{3}{*}{ Retrospective } & $70.3 \% \mathrm{HTN}$ & \multirow[t]{3}{*}{$1-3$ days post $-\mathrm{ICH}$} & \multirow[t]{3}{*}{$23 \%$} & $70.4 \%$ subcortical & \multirow[t]{3}{*}{$0.12-0.54 \mathrm{~mL}$ volume } & \multirow[t]{3}{*}{ Not mentioned } & \multirow{3}{*}{$\begin{array}{l}\text { Prabhakaran et al. } \\
\text { (27) }\end{array}$} \\
\hline & & $11.9 \% \mathrm{CAA}$ & & & $25.9 \%$ cortical & & & \\
\hline & & $13.6 \%$ anticoagulation & & & $3.7 \%$ mixed & & & \\
\hline \multirow[t]{2}{*}{$114(100 \% \mathrm{ICH})$} & \multirow[t]{2}{*}{$\begin{array}{l}\text { Multicenter } \\
\text { case-control }\end{array}$} & $34 \%$ CAA & \multirow[t]{2}{*}{$55 \%$ within 1 week } & $13 \%$ & $75 \%$ cortical or subcortical & $\begin{array}{l}\text { CAA 0.42-1.46 cm } \\
\text { diameter }\end{array}$ & \multirow[t]{2}{*}{ Not mentioned } & \multirow[t]{2}{*}{ Gregoire et al. (19) } \\
\hline & & $66 \%$ non-CAA & & $23 \%$ CAA & $25 \%$ other & $\begin{array}{l}\text { Non-CAA: } 0.25-1.50 \mathrm{~cm} \\
\text { diameter }\end{array}$ & & \\
\hline \multirow[t]{2}{*}{$95(100 \% \mathrm{ICH})$} & \multirow[t]{2}{*}{ Prospective } & $62 \%$ HTN & \multirow[t]{2}{*}{$0.8-7.5$ days } & \multirow[t]{2}{*}{$41 \%$} & \multirow[t]{2}{*}{ Not mentioned } & \multirow[t]{2}{*}{ Not mentioned } & \multirow[t]{2}{*}{ Not mentioned } & \multirow[t]{2}{*}{ Garg et al. (23) } \\
\hline & & $15 \%$ CAA & & & & & & \\
\hline \multirow[t]{2}{*}{$138(100 \% \mathrm{ICH})$} & \multirow[t]{2}{*}{ Prospective } & $62 \% \mathrm{HTN}$ & Baseline: mean 2 days & $\begin{array}{l}\text { Acute: } 35 \% \\
\text { Follow-up: } 27 \%\end{array}$ & Baseline: 44\% lobar & $\begin{array}{l}\text { Baseline: mean } 0.5 \mathrm{~mL} \\
\text { volume }\end{array}$ & $\begin{array}{l}\text { Single or } \\
\text { multiple }\end{array}$ & Menon et al. (26) \\
\hline & & $1.5 \%$ CAA & Follow-up: mean 35 days & & Follow-up: $13 \%$ lobar & 1 month: $0.4 \mathrm{~mL}$ volume & & \\
\hline 97 (100\% ICH) & Prospective & $100 \%$ HTN & Within 3 days & $26.80 \%$ & $75.5 \%$ subcortical or brainstem & $<3 \mathrm{~mm}$ diameter & $76.9 \%$ single & Kang et al. (24) \\
\hline & & & & & $24.5 \%$ cortical & & $23.1 \%$ multiple & \\
\hline $86(100 \% \mathrm{ICH})$ & Prospective & Not mentioned & Within 14 days & $17.40 \%$ & $47 \%$ isolated cortical & $86.7 \%$ small, dot-like & $47 \%$ single & Arsava et al. (18) \\
\hline & & & & & $47 \%$ subcortical with or without cortical & $13.3 \%$ larger, territorial & $53 \%$ multiple & \\
\hline & & & & & $7 \%$ isolated deep & & & \\
\hline $153(100 \% \mathrm{ICH})$ & Prospective & Mostly HTN & Baseline: within 2 weeks & $11.1 \%$ & $80 \%$ cortical or subcortical & Not mentioned & $64.7 \%$ single & Tsai et al. (20) \\
\hline & & & Follow-up: 3 months & $\begin{array}{l}52 \% \text { not visible in } \\
\text { follow-up }\end{array}$ & $20 \%$ deep, cerebellum, brainstem & & & \\
\hline $392(100 \% \mathrm{ICH})$ & Retrospective & $15.2 \%$ CAA & Acute: $\leq 7$ days & Acute: $18.2 \%$ & $87.4 \%$ lober & Not mentioned & Not mentioned & Auriel et al. (21) \\
\hline & & $17.2 \% \mathrm{HTN}$ & Nonacute: $\geq 14$ days & Nonacute: $12.9 \%$ & & & & \\
\hline $117(100 \% \mathrm{ICH})$ & Retrospective & $45.7 \% \mathrm{HTN}$ & $1-5$ days & $14.50 \%$ & $50 \%$ cortical & $0.44 \pm 0.3 \mathrm{~mL}$ volume & Not mentioned & Gioia et al. (9) \\
\hline & & $9.4 \%$ CAA & & & $47.6 \%$ subcortical & & & \\
\hline & & $8.5 \%$ anticoagulation & & & $2.4 \%$ infratentorial & & & \\
\hline & & $55.2 \%$ HTN & & & $46.4 \%$ cortical & & & \\
\hline $201(100 \% \mathrm{ICH})$ & Retrospective & $34.8 \%$ CAA & Within 1 month & $27.90 \%$ & $37.5 \%$ subcortical & $<20 \mathrm{~mm}$ diameter & 1-42 (median 2) & Wu et al. (22) \\
\hline & & $10 \%$ Warfarin-related & & & $14.3 \%$ deep & & & \\
\hline & & or undetermined & & & $1.8 \%$ cerebellum & & & \\
\hline
\end{tabular}

DWI, diffusion-weighted imaging; ICH, intracerebral hemorrhage; MB, microbleeds; CAA, cerebral amyloid angiopathy; HTN, hypertension; BP, blood pressure. 


\section{MICROANGIOPATHY}

Microangiopathy, also described as small vessel diseases (SVD), is a group of pathological processes affecting the small arteries, arterioles, venules, and capillaries of the brain. HA and CAA are considered as two major causes of SVD (40). Generally, the imaging demonstration of SVD mainly included cerebral microbleeds (CMBs), lacunar infarction, enlarged perivascular spaces (EPVS), and white matter hyperintensities (WMH). It was reported that DWI lesions were associated with CMBs (19, 20, 24-26), WMH $(9,19,20,24)$, and centrum semiovale (CSO)-EPVS (22). CMBs are regarded as small chronic brain hemorrhages, mostly caused by blood-brain barrier deficiency of the cerebral small vessels (41). It is already widely accepted that high incidence of CMB was related with high risk of spontaneous ICH (42), especially the CAA patients. The antemortem brain MRI-observed CMBs were found highly associated with cerebral microinfarcts (CMI) at autopsy in patients with neuropathologic evidence of CAA (43). For another major demonstrations SVD, the white matter lesions, it was usually regarded as evolving from a combination of demyelination, lacunar infarcts, and axonal loss, as well as venous congestion (44). Charidimou et al. have observed that different distribution of subcortical WMH on MRI might provide insights into different dominant arteriopathy (45). In the research, the prevalence of multiple subcortical spots was higher in the CAA compared to the HA group, and peri-BG WMH pattern was more common in the HA-ICH vs. the CAA-ICH group (45). Perivascular spaces (PVS), also called Virchow-Robin spaces, are extensions of the subarachnoid space that accompany penetrating vessels entering the brain parenchyma (46). EPVS were reported to be associated with age, lacunar stroke subtype, and white matter lesions in a prospective study (47). High degree of PVS in BG may represent HA etiology in spontaneous ICH patients, and high degree of CSO-PVS may represent CAA etiology in spontaneous ICH patients (47-50). As the data showed by Wu and his colleagues, high CSO-EPVS were significantly associated with small acute DWI lesions in ICH patients (22). These findings may imply that, an underlying SVD may play a role in the formation of DWI lesions. In fact, a new DWI lesion itself has also been assumed by some researchers as one of the neuroimaging markers for SVD (51).

\section{CEREBRAL ATHEROSCLEROSIS}

Cerebral atherosclerosis may account for almost one-third of ischemic strokes, and the underlying mechanisms include artery-to-artery embolism, hemodynamic compromise, local branch occlusion, or a combination of those conditions (52). In fact, intra- and extracranial atherosclerotic disease have also been detected in approximately one-fifth of patients with spontaneous ICH (53). It might be possible that cerebral atherosclerosis may contribute to the formation of DWI lesions after ICH through mechanisms mentioned before. By far, the research about the relationship between atherosclerosis and DWI lesions is rare currently, and the number of patients with cerebral angiograms performed in ICH is small. In one research, 21 patients (21.6\%) had diagnostic cerebral angiograms performed, and 1 had arterial stenosis relevant to DWI lesions (24). While in another research, the authors found no relation between cerebral atherosclerosis and DWI lesions (26). Besides, it is noteworthy that the relationship between cerebral atherosclerosis and DWI lesions may be partly due to the coexistence of SVD, as SVD and cerebral atherosclerosis often share common vascular risk factors like hypertension, diabetes mellitus, hyperlipidemia, and smoking (54-56). In fact, it is difficult to distinguish the effects of cerebral atherosclerosis from SVD completely. Some studies have reported that distal single small subcortical infarction (SSSI), according to the lesion location in relation to the parent artery, is closely associated with lipohyalinosis, while proximal infarction seems to be related with atherosclerosis $(57,58)$. As similar size between SSSI and remote DWI lesions, further studies may divide these ischemic lesions into distal or proximal infarction according to the lesion location in relation to the parent artery, and investigate whether indicators for SVD and atherosclerosis differ according to lesion location.

\section{BP LOWERING}

Although high BP are reported to be associated with hematoma expansion and poor outcome (59), BP management in the acute stage of ICH remains an issue of debate. When BP is lowered aggressively, several large studies failed to reveal remarkable improvements in clinical outcome (60-63). It is argued that aggressive BP lowering may also increase the possibility of cerebral hypoperfusion, and thus induce cerebral ischemia, which outweighs the benefits (64).

Autoregulation of the cerebral circulation is the regulating mechanism that keeps $\mathrm{CBF}$ constant within wide limits of arterial pressure (65). In chronic hypertension, this homeostasis is shifted toward higher arterial pressures, which impairs the tolerance to acute decreases in arterial pressure, while improving the tolerance to acute increases in arterial pressure (65). Thus, in the setting of $\mathrm{ICH}$, with intracranial pressure (ICP) elevation, the deficiency of $\mathrm{CBF}$ autoregulation is furtherly aggravated (65). Besides, within the cerebrovascular tree, distal arteries possess a substantially higher myogenic activity than proximal arteries, which could be more easily to be affected by chronic hypertension (44). Therefore, $\mathrm{BP}$ lowering might provoke cerebral ischemia in ICH patients with chronic hypertension, especially in the territory of distal arteries.

For decades, there are conflicting reports about the relationship between BP lowering and DWI lesions after ICH. Several studies found an association between the BP lowering and the DWI lesions after ICH $(20,23,26,27)$, while other studies failed to prove the association, including two recent studies (9, 22). This discrepancy may partly due to different study design, patient selection and MRI time. Besides, in these studies, BP values were observed at different time points (admission, lowest or highest values before MRI or some other time points) during the acute phase of $\mathrm{ICH}$, and the patients were not treated with the same protocol. In addition, BP lowering in most studies may not reflect true BP control, as it was merely calculated by maximal SBP drop. Gioia et al. attempted to assess global BP control over $24 \mathrm{~h}$ by assessing the weighted average BP over $24 \mathrm{~h}$ and found no relationship between DWI lesions and control of BP over the initial $24 \mathrm{~h}$ (9). It is argued that prospective observational study 
and randomized clinical trials are needed to test the hypothesis whether and to what extent BP lowering may provoke DWI lesions. In fact, a multicenter randomized trial-Intracerebral Hemorrhage Acutely Decreasing Arterial Pressure trial II (ICH ADAPT II) has been ongoing to specifically assess the rate of ischemic lesion development in patients randomized to two different BP treatment strategies (66).

\section{REMOTE EXTENSION OF HEMATOMA}

Recently, another etiology of ICH-related DWI lesions was proposed that hematoma may affect not only the primary site of ictus but also the remote regions, through PVS or perineurium possibly, according to the prior studies $(67,68)$. It was found that larger ICH volume has higher incidence of DWI lesions $(22,26)$. PVS, as mentioned before, are extensions of the subarachnoid space that accompany penetrating vessels when enter the brain parenchyma, and they serve as draining channels for the brain (46). PVS also collects and carries lymph from the brain parenchyma to the deep cervical lymph nodes (45). The perineurium represents a protective continuum with the pia-arachnoid in the central nervous system and surrounds nerve fascicles within the epineurium throughout the peripheral nervous system (69). A previous study in an $\mathrm{ICH}$ rat model has demonstrated that spot hemorrhagic lesions located in perihematomal tissues, which are usually named as ring hemorrhage for its ring shape surrounding the blood vessels, may be formed by blood overflow from hematomas along the PVS or the perineurium (68). In another $\mathrm{ICH}$ rat model, the formed blood elements (red blood cell) were observed to extend mainly into the PVS and perineurium in the perihematomal tissue and ipsilateral brain regions near the hematoma, and the soluble blood elements (bovine serum albumin) extended more extensively to almost all regions of the brain (44). In ICH patients, MRI with susceptibility weighted imaging (SWI) revealed that paramagnetic substances spread along the PVS or the perineurium and such distribution could cause the formation of CMBs $(70,71)$. These results indicated that blood constituents could extend through PVS and perineurium in ICH patients. Some reports support the notion that blood cell decomposition products such as iron, heme, and thrombin, as well as inflammatory cells, such as microglia and neutrophils, both contribute to the secondary perihematomal injury after ICH through various pathological pathways like cytotoxicity of blood, hypermetabolism, excitotoxicity, spreading depression, oxidative stress, and inflammation $(8,72)$. In $\mathrm{ICH}$, inflammation can destroy the blood-brain barrier of small vessels by impairing endothelial function, which furtherly lead to microvasculature disruption and promote clot formation. If this effect sustained, irreversible ischemic injury would occur $(73,74)$. Hence, toxic substances extended through PVS and perineurium may also result in remote ischemic injury. In clinical practice, Wu et al. have found that high prevalence of CSO-EPVS were significantly associated with DWI lesions in ICH patients (22). Still, these findings cannot exclude the impact of potential microangiopathy and further study about the effect of global inflammation is needed.

In addition, $\mathrm{He}$ et al. observed that both formed and soluble blood elements are drained to bilateral deep cervical lymph nodes, and the PVS dilation was closely related to the PHE (67). Therefore, extension of the hematoma may not only cause remote DWI lesions but also lymphostatic encephalopathy and PHE (67).

\section{VENOUS DRAINAGE DISORDER}

Zhang et al. has raised a new concept of Vascular Neural Network, which partially spawned from traditional Chinese medicine and pathophysiological understanding of stroke treatment strategies that arterial and venous blood flow needs to be in harmony (75). Recently, more and more studies revealed that venous system abnormality may play an important role in the process of cerebral ischemia. It is reported that in subarachnoid hemorrhage, when flow velocity in the basal vein was significantly elevated above normal values in the following day, patients were found without delayed ischemic neurological deficit, while when flow velocities in the basal vein were significantly below normal in the following day, patients were found to have permanent deficit $(76,77)$. In another study, prominent hypointense veins were seen on SWI at 4 days after acute infarction in the first and second medial gyrus (78).

The structures of cerebral veins are distinctly different from arteries. First, small veins and venules do not have encompassing smooth muscle cell, instead, a network of stellates or glia exist around venous walls as well as pericytes (79). Thus, venous cannot contract as strongly as arteries. Additionally, compared with arteries, cerebral veins possess no valves to prevent the backflow of venous blood $(80,81)$. Third, under the conditions of elevated ICP or regional brain edema, the thin walls of the venules and small veins would easily collapse since they can be compressed (81-83). In addition, leukocytes adhere to both arterial and venous endothelium in microcirculation, especially during the development of hypoxia, which could result in vascular occlusion, and venous system may be more vulnerable than arterial system for its slower blood flow $(74,84)$. An acute reduction of arterial flow at $20 \%$ may cause a mild and almost harmless episode of cerebral ischemia, but if the venous flow is decreased acutely by $20 \%$, blood may be accumulated in the capillary system, leading to an increase in ICP, flow decrease, even venous infarction (81). Thus, it is presumed that the venous system may change passively along with increased cerebral blood volume, hypertension, and mechanical compression, which may influence circulation flow, and lead to cerebral ischemia.

In the setting of ICH, ICP is first increased by hematoma, and then the cytotoxic and vasogenic edema even accelerate the PHE. All these factors come to compress related venous structures and hence result in a vicious cycle. So far, few studies about the potential roles of venous side in DWI lesions after ICH have been reported. In future, both animal and human studies are needed to evaluate venous system disorder after ICH and its function in SBI including DWI lesions. Besides, imaging technologies detected small vein and venule also have to be developed.

\section{CLINICAL OUTCOMES}

Most DWI lesions have been reported to be subclinical and did not lead to any neurologic deficit in the acute stage of ICH. Nonetheless, whether the presence of DWI lesions can predict 
poor functional outcome is still under debate. In a prospective study with 95 patients enrolled, DWI lesions were associated with nearly five times risk of dependence or death at 3 months after controlling other confounding factors (23). Kang et al. found that DWI lesions were an independent predictor of the composite of ischemic stroke and recurrent $\mathrm{ICH}$, as well as vascular deaths during a median follow-up of 42 months (24). However, in another larger prospective study with 153 patients enrolled, the author failed to find relation between DWI lesions and functional outcomes at 3 months, and interestingly, they found the patients with more DWI lesions, which were not visible on follow-up T2WI or FLAIR images had favorable outcomes (20). As mentioned before, it was hypothesized that regression of a DWI lesion may indicate a minor vasculopathy and a transient vascular occlusion with early reperfusion (20).

However, these studies have certain limitations. For example, the time interval of a MRI scan after ICH varies, the frequency of MRI scan is only once or twice, the number of patients with DWI lesions is small, and observation period is different. Besides, cognitive outcomes are rarely reported among these studies. CMI is not only a major contributor to function disorder in humans but also an important cause of vascular or mixed dementia and gait disorder (85-87), and lesions on DWI have been supposed to represent acute CMI (88). In a prospective cohort study, a substantial risk of incident dementia (14.2\%) was observed in dementia-free survivors of $\mathrm{ICH}$ at 1 year, and underlying CAA may be a contributing factor to the new occurrence (89). It was reported that detecting even a single DWI lesion may suggest a remarkable annual incidence of hundreds of new CMI (90). And a similar situation seems also exist in the patients with DWI lesions after ICH. In a prospective study, Menon et al. have found $87 \%$ of patients with DWI lesions at 1 month had one or more new DWI lesions compared to baseline, and $83 \%$ of all lesions at 1 month were new compared to baseline (26). As the cumulative effects of DWI lesions may lead to cognitive impairment, future clinical trials including patients with ICH should assess cognitive endpoints, which may need longer observation.

\section{THERAPEUTIC IMPLICATION}

The safety of aggressive BP lowering at early stage of ICH has been concerned for decades. The Intensive BP Reduction in Acute Cerebral Hemorrhage 2 (INTERACT2) trial reported no reduction in the rate of death or severe disability, although did find improved functional outcomes in those with more intensive BP control (61). The most recent Antihypertensive Treatment of Acute Cerebral Hemorrhage II trial also showed no difference in the rate of death or disability with intensive BP lowering compared to standard reduction, but a higher rate of serious and renal adverse events (62). These trials did not assess the small DWI lesions after ICH, which are usually silent, and do not cause significant neurological deficiency. Under the condition of remote extension of hematoma and venous drainage disorder secondary to $\mathrm{ICH}$, BP lowering was proposed to be easier to trigger ischemic lesions, especially in the patients with microangiopathy and cerebral atherosclerosis. Further studies with serial MRI are necessary to definitively determine whether and to what extent BP reduction is causally related to DWI lesions after ICH, and whether DWI lesions may modify the effect of BP lowering on long-term outcomes after ICH. Antiplatelet therapy might slightly increase the incidence of reoccurrence of ICH (91). However, the risk of immediate and delayed ICH from initiating antiplatelet therapy after ICH must be weighed against the morbidity of thrombotic complications, especially in patients with DWI lesions, for their implying of stroke (IS or ICH)-prone state after ICH. And statin therapy would face the same problem. As patients with cerebral angiography and AF may confront a substantially heightened risk of DWI lesions after ICH, whether and when to apply anticoagulation therapy in these patients requires further study. Given the substantial important role of venous system, future clinical management of ICH should include the recirculation concept, which focuses on the harmony between arterial and venous systems. In a word, the etiology of DWI lesions varies, thus for every patient, treatment requires individual concerns.

\section{SUMMARY}

In conclusion, small DWI lesions are common in the regions remote from the hematoma in the acute phase of $\mathrm{ICH}$, and the occurrence may be mainly in the subacute phase of ICH. These lesions have been generally considered as ischemic infarcts. Mechanisms of these lesions after ICH are still unclear. According to the recent publications, several factors may play potential roles, including microangiopathy, CAA, BP lowering, remote extension of hematoma, venous drainage disorder. These lesions are often subclinical, but may be associated with worsened long-term outcome. After all, the occurrence of DWI lesions may help to differentiate the stroke-prone patients after ICH, in which BP lowering and other treatment should be applied more cautiously and individually.

\section{ETHICS STATEMENT}

The study protocol has been approved by the institutional Human Research Ethics Committee of the second affiliated hospital of Zhejiang university.

\section{AUTHOR CONTRIBUTIONS}

$\mathrm{X}$-hX: bring up the idea and write the original review. TG: search for papers and help to write the original review. W-jZ: suggest some useful points about the structure of review. L-sT: help to revise the whole framework and polish the language. FG: help to revise the whole framework and polish the language.

\section{FUNDING}

National Natural Science Foundation of China (NSFC) (81471168) to FG, National Natural Science Foundation of China (NSFC) (81500991) to L-sT, Foundation of Zhejiang Educational Committee (Y201738067) to X-hX, Medical Scientific Research Foundation of Zhejiang Province (2018250144) to X-hX. 


\section{REFERENCES}

1. de Oliveira Manoel AL, Goffi A, Zampieri FG, Turkel-Parrella D, Duggal A, Marotta TR, et al. The critical care management of spontaneous intracranial hemorrhage: a contemporary review. Crit Care (2016) 20:272. doi:10.1186/ s13054-016-1432-0

2. Caplan LR. Intracerebral haemorrhage. Lancet (1992) 339(8794):656-8. doi:10.1016/0140-6736(92)90804-C

3. Feigin VL, Lawes CM, Bennett DA, Barker-Collo SL, Parag V. Worldwide stroke incidence and early case fatality reported in 56 population-based studies: a systematic review. Lancet Neurol (2009) 8:355-69. doi:10.1016/ S1474-4422(09)70025-0

4. Tsai CF, Thomas B, Sudlow CL. Epidemiology of stroke and its subtypes in Chinese vs white populations: a systematic review. Neurology (2013) 81:264. doi:10.1212/WNL.0b013e31829bfde3

5. Liu J, Wang D, Yuan R, Xiong Y, Liu M. Prognosis of 908 patients with intracerebral hemorrhage in Chengdu, Southwest of China. Int J Neurosci (2016) 127:586-91. doi:10.1080/00207454.2016.1216414

6. Kim H, Edwards NJ, Choi HA, Chang TR, Jo KWLee K. Treatment strategies to attenuate perihematomal edema in patients with intracerebral hemorrhage. World Neurosurg (2016) 94:32-41. doi:10.1016/j.wneu.2016.06.093

7. Belur PK, Chang JJ, He S, Emanuel BA, Mack WJ. Emerging experimental therapies for intracerebral hemorrhage: targeting mechanisms of secondary brain injury. Neurosurg Focus (2013) 34:E9. doi:10.3171/2013.2.FOCUS1317

8. Aronowski J, Zhao X. Molecular pathophysiology of cerebral hemorrhage: secondary brain injury. Stroke (2011) 42:1781-6. doi:10.1161/ STROKEAHA.110.596718

9. Gioia LC, Kate M, Choi V, Sivakumar L, Jeerakathil T, Kosior J, et al. Ischemia in intracerebral hemorrhage is associated with leukoaraiosis and hematoma volume, not blood pressure reduction. Stroke (2015) 46:1541-7. doi:10.1161/ STROKEAHA.114.008304

10. Gould B, McCourt R, Gioia LC, Kate M, Hill MD, Asdaghi N, et al. Acute blood pressure reduction in patients with intracerebral hemorrhage does not result in borderzone region hypoperfusion. Stroke (2014) 45:2894-9. doi:10.1161/STROKEAHA.114.005614

11. Kuang Y, Chen W, Zheng K, Fu J, Hu Z, Yang Y, et al. [CT perfusion imaging evaluation on hemodynamic changes of acute spontaneous intracerebral hemorrhage surrounding tissues]. Zhonghua Yi Xue Za Zhi (2015) 95:3514-8. doi:10.3760/cma.j.issn.0376-2491.2015.43.008

12. Zhou J, Zhang H, Gao P, Lin Y, Li X. Assessment of perihematomal hypoperfusion injury in subacute and chronic intracerebral hemorrhage by CT perfusion imaging. Neurol Res (2010) 32:642-9. doi:10.1179/0161641 09X12445616596328

13. Zhao X, Wang Y, Wang C, Li S, Wang Y, Yang Z. Quantitative evaluation for secondary injury to perihematoma of hypertensive cerebral hemorrhage by functional MR and correlation analysis with ischemic factors. Neurol Res (2006) 28:66-70. doi:10.1179/016164106X91898

14. Tayal AH, Gupta R, Yonas H, Jovin T, Uchino K, Hammer M, et al. Quantitative perihematomal blood flow in spontaneous intracerebral hemorrhage predicts in-hospital functional outcome. Stroke (2007) 38:319-24. doi:10.1161/01. STR.0000254492.35504.db

15. Herweh C, Juttler E, Schellinger PD, Klotz E, Jenetzky E, Orakcioglu B, et al. Evidence against a perihemorrhagic penumbra provided by perfusion computed tomography. Stroke (2007) 38:2941-7. doi:10.1161/STROKEAHA. 107.486977

16. Pascual AM, Lopez-Mut JV, Benlloch V, Chamarro R, Soler J, Lainez MJ. Perfusion-weighted magnetic resonance imaging in acute intracerebral hemorrhage at baseline and during the 1st and 2nd week: a longitudinal study. Cerebrovasc Dis (2007) 23:6-13. doi:10.1159/000095752

17. Mayer SA, Lignelli A, Fink ME, Kessler DB, Thomas CE, Swarup R, et al. Perilesional blood flow and edema formation in acute intracerebral hemorrhage: a SPECT study. Stroke (1998) 29:1791-8. doi:10.1161/01.STR.29.9.1791

18. Arsava EM, Kayim-Yildiz O, Oguz KK, Akpinar E, Topcuoglu MA. Elevated admission blood pressure and acute ischemic lesions in spontaneous intracerebral hemorrhage. J Stroke Cerebrovasc Dis (2013) 22:250-4. doi:10.1016/j. jstrokecerebrovasdis.2011.08.006

19. Gregoire SM, Charidimou A, Gadapa N, Dolan E, Antoun N, Peeters A, et al. Acute ischaemic brain lesions in intracerebral haemorrhage: multicentre cross-sectional magnetic resonance imaging study. Brain (2011) 134:2376-86. doi:10.1093/brain/awr172

20. Tsai YH, Lee MH, Weng HH, Chang SW, Yang JT, Huang YC. Fate of diffusion restricted lesions in acute intracerebral hemorrhage. PLoS One (2014) 9:e105970. doi:10.1371/journal.pone.0105970

21. Auriel E, Gurol ME, Ayres A, Dumas AP, Schwab KM, Vashkevich A, et al. Characteristic distributions of intracerebral hemorrhage-associated diffusion-weighted lesions. Neurology (2012) 79:2335-41. doi:10.1212/ WNL.0b013e318278b66f

22. Wu B, Yao X, Lei C, Liu M, Selim MH. Enlarged perivascular spaces and small diffusion-weighted lesions in intracerebral hemorrhage. Neurology (2015) 85:2045-52. doi:10.1212/WNL.0000000000002169

23. Garg RK, Liebling SM, Maas MB, Nemeth AJ, Russell EJ, Naidech AM. Blood pressure reduction, decreased diffusion on MRI, and outcomes after intracerebral hemorrhage. Stroke (2012) 43:67-71. doi:10.1161/ STROKEAHA.111.629493

24. Kang DW, Han MK, Kim HJ, Yun SC, Jeon SB, Bae HJ, et al. New ischemic lesions coexisting with acute intracerebral hemorrhage. Neurology (2012) 79:848-55. doi:10.1212/WNL.0b013e3182648a79

25. Kimberly WT, Gilson A, Rost NS, Rosand J, Viswanathan A, Smith EE, et al. Silent ischemic infarcts are associated with hemorrhage burden in cerebral amyloid angiopathy. Neurology (2009) 72:1230-5. doi:10.1212/01. wnl.0000345666.83318.03

26. Menon RS, Burgess RE, Wing JJ, Gibbons MC, Shara NM, Fernandez S, et al. Predictors of highly prevalent brain ischemia in intracerebral hemorrhage. Ann Neurol (2012) 71:199-205. doi:10.1002/ana.22668

27. Prabhakaran S, Gupta R, Ouyang B, John S, Temes RE, Mohammad Y, et al. Acute brain infarcts after spontaneous intracerebral hemorrhage: a diffusion-weighted imaging study. Stroke (2010) 41:89-94. doi:10.1161/ STROKEAHA.109.566257

28. Kim BJ, Kang HG, Kim HJ, Ahn SH, Kim NY, Warach S, et al. Magnetic resonance imaging in acute ischemic stroke treatment. J Stroke (2014) 16:131-45. doi:10.5853/jos.2014.16.3.131

29. Attems J, Jellinger K, Thal DR, Van Nostrand W. Review: sporadic cerebral amyloid angiopathy. Neuropathol Appl Neurobiol (2011) 37:75-93. doi:10.1111/j.1365-2990.2010.01137.x

30. Acampa M, Guideri F, Di Donato I, Tassi R, Marotta G, Lo Giudice G, et al. Arterial stiffness in patients with deep and lobar intracerebral hemorrhage. J Stroke (2014) 16:184-8. doi:10.5853/jos.2014.16.3.184

31. Lang EW, Ren Ya Z, Preul C, Hugo HH, Hempelmann RG, Buhl R, et al. Stroke pattern interpretation: the variability of hypertensive versus amyloid angiopathy hemorrhage. Cerebrovasc Dis (2001) 12:121-30. doi:10.1159/ 000047691

32. Ritter MA, Droste DW, Hegedus K, Szepesi R, Nabavi DG, Csiba L, et al. Role of cerebral amyloid angiopathy in intracerebral hemorrhage in hypertensive patients. Neurology (2005) 64:1233-7. doi:10.1212/01. WNL.0000156522.93403.C3

33. Rodrigue KM, Rieck JR, Kennedy KM, Devous MD Sr, Diaz-Arrastia R, Park DC. Risk factors for beta-amyloid deposition in healthy aging: vascular and genetic effects. JAMA Neurol (2013) 70:600-6. doi:10.1001/jamaneurol. 2013.1342

34. Zhan RY, Tong Y, Shen JF, Lang E, Preul C, Hempelmann RG, et al. Study of clinical features of amyloid angiopathy hemorrhage and hypertensive intracerebral hemorrhage. J Zhejiang Univ Sci (2004) 5:1262-9. doi:10.1631/ jzus.2004.1262

35. Peters JM, Maclean AV, Young GS. Rapid resolution of diffusion weighted MRI abnormality in a patient with a stuttering stroke. BMJ Case Rep (2010) 2010. doi:10.1136/bcr.07.2009.2063

36. Terasawa Y, Iguchi Y, Kimura K, Kobayashi K, Aoki J, Shibazaki K. Reversible diffusion-weighted lesion in a TIA patient without arterial recanalization: a case report. J Neurol Sci (2008) 272:183-5. doi:10.1016/j.jns.2008.04.033

37. Albach FN, Brunecker P, Usnich T, Villringer K, Ebinger M, Fiebach JB, et al. Complete early reversal of diffusion-weighted imaging hyperintensities after ischemic stroke is mainly limited to small embolic lesions. Stroke (2013) 44:1043-8. doi:10.1161/STROKEAHA.111.676346

38. Asdaghi N, Campbell BC, Butcher KS, Coulter JI, Modi J, Qazi A, et al. DWI reversal is associated with small infarct volume in patients with TIA and minor stroke. Am J Neuroradiol (2014) 35:660-6. doi:10.3174/ajnr.A3733 
39. Kidwell CS, Rosand J, Norato G, Dixon S, Worrall BB, James ML, et al. Ischemic lesions, blood pressure dysregulation, and poor outcomes in intracerebral hemorrhage. Neurology (2017) 88:782. doi:10.1212/WNL.0000000000003630

40. Boulouis G, Charidimou A, Auriel E, Haley KE, van Etten ES, Fotiadis P, et al. Intracranial atherosclerosis and cerebral small vessel disease in intracerebral hemorrhage patients. J Neurol Sci (2016) 369:324-9. doi:10.1016/j. jns.2016.08.049

41. Helenius J, Mayasi Y, Henninger N. White matter hyperintensity lesion burden is associated with the infarct volume and 90-day outcome in small subcortical infarcts. Acta Neurol Scand (2017) 135:585-92. doi:10.1111/ane.12670

42. Pasquini M, Benedictus MR, Boulouis G, Rossi C, Dequatre-Ponchelle N, Cordonnier C. Incident cerebral microbleeds in a cohort of intracerebral hemorrhage. Stroke (2016) 47:689-94. doi:10.1161/STROKEAHA.115.011843

43. Lauer A, van Veluw SJ, William CM, Charidimou A, Roongpiboonsopit D, Vashkevich A, et al. Microbleeds on MRI are associated with microinfarcts on autopsy in cerebral amyloid angiopathy. Neurology (2016) 42(3-4):255-62. doi:10.1212/WNL.0000000000003184

44. Meissner A. Hypertension and the brain: a risk factor for more than heart disease. Cerebrovasc Dis (2016) 42:255-62. doi:10.1159/000446082

45. Charidimou A, Boulouis G, Haley K, Auriel E, van Etten ES, Fotiadis P, et al. White matter hyperintensity patterns in cerebral amyloid angiopathy and hypertensive arteriopathy. Neurology (2016) 86:505-11. doi:10.1212/ WNL.0000000000002362

46. Ogawa T, Okudera T, Fukasawa H, Hashimoto M, Inugami A, Fujita H, et al. Unusual widening of Virchow-Robin spaces: MR appearance. AJNR Am J Neuroradiol (1995) 16(6):1238-42.

47. Potter GM, Doubal FN, Jackson CA, Chappell FM, Sudlow CL, Dennis MS, et al. Enlarged perivascular spaces and cerebral small vessel disease. Int J Stroke (2015) 10:376-81. doi:10.1111/ijs.12054

48. Yakushiji Y, Charidimou A, Hara M, Noguchi T, Nishihara M, Eriguchi M, et al. Topography and associations of perivascular spaces in healthy adults: the Kashima scan study. Neurology (2014) 83:2116-23. doi:10.1212/ WNL.0000000000001054

49. Charidimou A, Jaunmuktane Z, Baron JC, Burnell M, Varlet P, Peeters A, et al. White matter perivascular spaces: an MRI marker in pathology-proven cerebral amyloid angiopathy? Neurology (2014) 82:57-62. doi:10.1212/01. wnl.0000438225.02729.04

50. Charidimou A, Meegahage R, Fox Z, Peeters A, Vandermeeren Y, Laloux P, et al. Enlarged perivascular spaces as a marker of underlying arteriopathy in intracerebral haemorrhage: a multicentre MRI cohort study. J Neurol Neurosurg Psychiatry (2013) 84:624-9. doi:10.1136/jnnp-2012-304434

51. Wardlaw JM, Smith EE, Biessels GJ, Cordonnier C, Fazekas F, Frayne R, et al. Neuroimaging standards for research into small vessel disease and its contribution to ageing and neurodegeneration. Lancet Neurol (2013) 12:822-38. doi:10.1016/S1474-4422(13)70124-8

52. Gao T, Wei YU, Liu C. Mechanisms of ischemic stroke in patients with intracranial atherosclerosis: a high-resolution magnetic resonance imaging study. Exp Ther Med (2014) 7:1415-9. doi:10.3892/etm.2014.1600

53. Sato S, Uehara T, Hayakawa M, Nagatsuka K, Minematsu K, Toyoda K. Intraand extracranial atherosclerotic disease in acute spontaneous intracerebral hemorrhage. J Neurol Sci (2013) 332:116-20. doi:10.1016/j.jns.2013.06.031

54. Kandiah N, Goh O, Mak E, Marmin M, Ng A. Carotid stenosis: a risk factor for cerebral white-matter disease. J Stroke Cerebrovasc Dis (2014) 23:136-9. doi:10.1016/j.jstrokecerebrovasdis.2012.11.007

55. Bos D, Vernooij MW, Elias-Smale SE, Verhaaren BF, Vrooman HA, Hofman A, et al. Atherosclerotic calcification relates to cognitive function and to brain changes on magnetic resonance imaging. Alzheimers Dement (2012) 8:S104-11. doi:10.1016/j.jalz.2012.01.008

56. Wu XH, Chen XY, Wang LJ, Sing WK. Intracranial artery calcification and its clinical significance. JClin Neurol (2016) 12:253-61. doi:10.3988/ jen.2016.12.3.253

57. Wen L, Feng J, Zheng D. Heterogeneity of single small subcortical infarction can be reflected in lesion location. Neurol Sci (2013) 34:1109-16. doi:10.1007/ s10072-012-1187-6

58. Nah HW, Kang DW, Kwon SU, Kim JS. Diversity of single small subcortical infarctions according to infarct location and parent artery disease: analysis of indicators for small vessel disease and atherosclerosis. Stroke (2010) 41:2822-7. doi:10.1161/STROKEAHA.110.599464
59. Willmot M, Leonardi-Bee J, Bath PM. High blood pressure in acute stroke and subsequent outcome: a systematic review. Hypertension (2004) 43:18. doi:10.1161/01.HYP.0000105052.65787.35

60. Anderson CS, Huang Y, Wang JG, Arima H, Neal B, Peng B, et al. Intensive blood pressure reduction in acute cerebral haemorrhage trial (INTERACT): a randomised pilot trial. Lancet Neurol (2008) 7:391-9. doi:10.1016/S14744422(08)70069-3

61. Anderson CS, Heeley E, Huang Y, Wang J, Stapf C, Delcourt C, et al. Rapid blood-pressure lowering in patients with acute intracerebral hemorrhage. $N$ Engl J Med (2013) 368:2355-65. doi:10.1056/NEJMoa1214609

62. Qureshi AI, Palesch YY, Barsan WG, Hanley DF, Hsu CY, Martin RL, et al. Intensive blood-pressure lowering in patients with acute cerebral hemorrhage. N Engl J Med (2016) 375:1033-43. doi:10.1056/NEJMoa1603460

63. Bath PM, Woodhouse L, Scutt P, Krishnan K, Wardlaw JM, Bereczki D, et al. Efficacy of nitric oxide, with or without continuing antihypertensive treatment, for management of high blood pressure in acute stroke (ENOS): a partial-factorial randomised controlled trial. Lancet (2015) 385:617-28. doi:10.1016/S0140-6736(14)61121-1

64. Lai CL, Kuo RN, Chen HM, Chen MF, Chan KA, Lai MS. Risk of ischemic stroke during the initiation period of alpha-blocker therapy among older men. CMAJ (2016) 188:255-60. doi:10.1503/cmaj.150624

65. Paulson OB, Waldemar G, Schmidt JF, Strandgaard S. Cerebral circulation under normal and pathologic conditions. Am J Cardiol (1989) 63:2C-5C doi:10.1016/0002-9149(89)90396-2

66. Gioia L, Klahr A, Kate M, Buck B, Dowlatshahi D, Jeerakathil T, et al. The intracerebral hemorrhage acutely decreasing arterial pressure trial II (ICH ADAPT II) protocol. BMC Neurol (2017) 17:100. doi:10.1186/s12883-017-0884-4

67. He G, Lu T, Lu B, Xiao D, Yin J, Liu X, et al. Perivascular and perineural extension of formed and soluble blood elements in an intracerebral hemorrhage rat model. Brain Res (2012) 1451:10-8. doi:10.1016/j.brainres.2012.02.069

68. Tian-Ming L, Bing-Xun LU, Yin J. Piping phenomenon in process of hematoma formation of intracerebral hemorrhage. Chin J Geriatr Heart Brain Vessel Dis (2007) 9:489-91. doi:10.3969/j.issn.1009-0126.2007.07.017

69. Shanthaveerappa TR, Bourne GH. Perineural epithelium: a new concept of its role in the integrity of the peripheral nervous system. Science (1966) 154:1464-7. doi:10.1126/science.154.3755.1464

70. Yin J, Lu TM, Qiu G, Huang RY, Fang M, Wang YY, et al. Intracerebral hematoma extends via perivascular spaces and perineurium. Tohoku J Exp Med (2013) 230:133-9. doi:10.1620/tjem.230.133

71. Brouwers HB, Greenberg SM. Hematoma expansion following acute intracerebral hemorrhage. Cerebrovasc Dis (2013) 35:195-201. doi:10.1159/000346599

72. Zhao X, Aronowski J. Nrf2 to pre-condition the brain against injury caused by products of hemolysis after ICH. Transl Stroke Res (2013) 4:71-5. doi:10.1007/ s12975-012-0245-y

73. Tian GH, Sun K, Huang P, Zhou CM, Yao HJ, Huo ZJ, et al. Long-term stimulation with electroacupuncture at DU20 and ST36 rescues hippocampal neuron through attenuating cerebral blood flow in spontaneously hypertensive rats. Evid Based Complement Alternat Med (2013) 2013:482947. doi: $10.1155 / 2013 / 482947$

74. Duan X, Wen Z, Shen H, Shen M, Chen G. Intracerebral hemorrhage, oxidative stress, and antioxidant therapy. Oxid Med Cell Longev (2016) 2016:1203285. doi:10.1155/2016/1203285

75. Li Q, Khatibi N, Zhang JH. Vascular neural network: the importance of vein drainage in stroke. Transl Stroke Res (2014) 5:163-6. doi:10.1007/ s12975-014-0335-0

76. Mursch K, Wachter A, Radke K, Buhre W, Al-Sufi S, Munzel U, et al. Blood flow velocities in the basal vein after subarachnoid haemorrhage. A prospective study using transcranial duplex sonography. Acta Neurochir (Wien) (2001) 143:793-9; discussion 99-800. doi:10.1007/s007010170033

77. Yu W, Rives J, Welch B, White J, Stehel E, Samson D. Hypoplasia or occlusion of the ipsilateral cranial venous drainage is associated with early fatal edema of middle cerebral artery infarction. Stroke (2009) 40:3736-9. doi:10.1161/ STROKEAHA.109.563080

78. Kim YW, Kim HJ, Choi SH, Kim DC. Prominent hypointense veins on susceptibility weighted image in the cat brain with acute infarction: DWI, SWI, and PWI. Acta Radiol (2014) 55:1008-14. doi:10.1177/0284185113508181

79. Kawamura S, Yasui N. Observation of the blood-brain barrier function and vasomotor response in rat microcirculation using intravital 
fluorescence microscopy. Exp Neurol (1992) 117:247-53. doi:10.1016/00144886(92)90133-B

80. Kilic T, Akakin A. Anatomy of cerebral veins and sinuses. Front Neurol Neurosci (2008) 23:4-15. doi:10.1159/0000111256

81. Zhang JH. Vascular neural network in subarachnoid hemorrhage. Transl Stroke Res (2014) 5:423-8. doi:10.1007/s12975-014-0355-9

82. Chen J, Wang XM, Luan LM, Chao BT, Pang B, Song H, et al. Biological characteristics of the cerebral venous system and its hemodynamic response to intracranial hypertension. Chin Med J (Engl) (2012) 125:1303-9. doi:10.3760/ cma.j.issn.0366-6999.2012.07.021

83. Yu Y, Chen J, Si Z, Zhao G, Xu S, Wang G, et al. The hemodynamic response of the cerebral bridging veins to changes in ICP. Neurocrit Care (2010) 12:117-23. doi:10.1007/s12028-009-9299-4

84. Mel'nikova NN, Ivanov KP. [Leukocyte adhesion to walls of the rat pial venules in normoxia and during brain ischemia]. Ross Fiziol Zh Im I M Sechenova (2004) 90:1129-37.

85. Huijts M, Duits A, Staals J, Kroon AA, de Leeuw PW, van Oostenbrugge RJ. Basal ganglia enlarged perivascular spaces are linked to cognitive function in patients with cerebral small vessel disease. Curr Neurovasc Res (2014) 11:136-41. doi:10.2174/1567202611666140310102248

86. Hilal S, Sikking E, Shaik MA, Chan QL, van Veluw SJ, Vrooman H, et al. Cortical cerebral microinfarcts on 3T MRI: a novel marker of cerebrovascular disease. Neurology (2016) 87(15):1583-90. doi:10.1212/WNL.0000000000003110

87. Coban H, Tung S, Yoo B, Vinters HV, Hinman JD. Molecular disorganization of axons adjacent to human cortical microinfarcts. Front Neurol (2017) 8:405. doi:10.3389/fneur.2017.00405
88. Smith EE, Schneider JA, Wardlaw JM, Greenberg SM. Cerebral microinfarcts: the invisible lesions. Lancet Neurol (2012) 11(3):272-82. doi:10.1016/ S1474-4422(11)70307-6

89. Moulin S, LabreucheJ,BomboisS, Rossi C, Boulouis G, Henon H, etal. Dementia risk after spontaneous intracerebral haemorrhage: a prospective cohort study. Lancet Neurol (2016) 15:820-9. doi:10.1016/S1474-4422(16)00130-7

90. Auriel E, Westover MB, Bianchi MT, Reijmer Y, Martinez-Ramirez S, Ni J, et al. Estimating total cerebral microinfarct burden from diffusion-weighted imaging. Stroke (2015) 46:2129-35. doi:10.1161/STROKEAHA.115.009208

91. Baharoglu MI, Cordonnier C, Al-Shahi Salman R, de Gans K, Koopman MM, Brand A, et al. Platelet transfusion versus standard care after acute stroke due to spontaneous cerebral haemorrhage associated with antiplatelet therapy (PATCH): a randomised, open-label, phase 3 trial. Lancet (2016) 387:2605-13. doi:10.1016/S0140-6736(16)30392-0

Conflict of Interest Statement: The authors declare that the research was conducted in the absence of any commercial or financial relationships that could be construed as a potential conflict of interest.

The reviewer WK and handling editor declared their shared affiliation.

Copyright $\odot 2017 \mathrm{Xu}, \mathrm{Gao}$, Zhang, Tong and Gao. This is an open-access article distributed under the terms of the Creative Commons Attribution License (CC BY). The use, distribution or reproduction in other forums is permitted, provided the original author(s) or licensor are credited and that the original publication in this journal is cited, in accordance with accepted academic practice. No use, distribution or reproduction is permitted which does not comply with these terms. 